\title{
Factors limiting successful reproduction in wild silver carp, Hypophthalmichtys molitrix, in Kherrata Reservoir, Algeria
}

\author{
Soraya Sadouni, Mokrane Iguer-Ouada
}

Received - 09 April 2018/Accepted - 04 September 2019. Published online: 30 September 2019; Inland Fisheries Institute in Olsztyn, Poland Citation: Sadouni S., Iguer-Ouada M. 2019 - Factors limiting successful reproduction in wild silver carp, Hypophthalmichtys molitrix, in

Kherrata Reservoir, Algeria - Fish. Aquat. Life 27: 159-168.

\begin{abstract}
Silver carp, Hypophthalmichtys molitrix (Cyprinidae), is the most important freshwater fish in Algerian aquaculture. No natural spawning is observed in Algerian water bodies. This study was conducted with the aim of investigating silver carp reproduction in the wild in Algeria. This investigation can contribute tools to facilitate successful artificial reproduction. Macroscopic and histological analysis of the gonads was conducted, and the monthly distribution of maturity stages and oocyte diameters were monitored in an aggregate sample of 130 male and female silver carp, $H$. molitrix, (450-710 $\mathrm{mm}$ total length). The gonadosomatic index (GSI) ranged from 2.76 to $18.88 \%$ in females and from 0.34 to $1.85 \%$ in males. The female GSI values were the highest from June to August indicating the onset of the spawning season. The histological structures of the gonads revealed five different developmental stages in females and three stages in males. The oogenesis stages were the perinucleolar stage, the yolk vesicle stage, the primary yolk, the secondary yolk, and the tertiary yolk. Migratory nuclei and hydrated oocytes, which are considered to be the maturation stage, were not observed. Three different spermatogenesis
\end{abstract}

S. Sadouni [ $\left.\Xi^{\circ}\right]$, M. Iguer-Ouada

Laboratoire Associé en Écosystèmes Marins et Aquaculture

Faculté des Sciences de la Nature et de la Vie, Université de Bejaia, 06000 Bejaia, Algérie

e-mail: sadsoraya1@gmail.com

\section{S. Sadouni}

National Center for Research and Development of Fisheries and Aquaculture (CNRDPA), Division of Aquaculture, Bou-ismail, Tipaza, Algeria phases (immature, maturing, and mature testis) were identified, which included final spermatozoa maturation.

Keywords: Algeria, Hypophthalmichtys molitrix, Kherrata Reservoir, limiting factors, reproduction, seasonal changes

\section{Introduction}

Silver carp, Hypophthalmichtys molitrix (Val.), is one of the most important freshwater fish species in aquaculture. Cyprinus carpio L. and other closely-related Cyprinidae species constitute over $30 \%$ of aquaculture production in the world (Xu et al. 2011). Despite the fact that silver carp has been introduced in many countries of the world for biological control (algal blooms) and aquaculture, natural reproduction is only observed in limited localities in ecosystems similar to those of the original environment (Kolar et al. 2005). Indeed, Stott and Cross (1973) noted that natural silver carp reproduction is only observed at four sites: the River Tone in Japan, the Ah Kung Tian Reservoir in Taiwan, the Amu-Darya River in Turkmenistan, and the Kuban River in the Caucasus. Later reports indicate that natural reproduction also occurs in the Kara Kum Canal in the Murghab River in Turkmenistan, and the Syr

(c) Copyright by Stanisław Sakowicz Inland Fisheries Institute in Olsztyn.

C 2019 Author(s). This is an open access article licensed under the Creative Commons Attribution-NonCommercial-NoDerivs License (http://creativecommons.org/licenses/by-nc-nd/3.0/). 
Darya River in Uzbekistan (Krykhtin and Gorbach 1981), in the Mississippi River (Herborg et al. 2007), the Missouri River (Schrank and Guy 2002), the Danube River (Jankovic 1998), and the Terek River in the Caucasus (Abdusamadov 1986).

In Algeria, silver carp stocking is performed in several provinces throughout the country, but no natural spawning is observed. The aim of the current study was to examine changes in the macroscopic and microscopic structures of the ovaries and testes of $H$. molitrix from Kherrata Reservoir. The experimental design consisted of investigating male and female gonad activity at the macroscopic level throughout two successive reproductive seasons and at the microscopic level during the annual maturation cycle.

\section{Materials and methods}

\section{Description of study area}

Kherrata Dam Reservoir (710 ha) is located in northeast Algeria in the region of Bejaia ( $36^{\circ} 28^{\prime} 16.07^{\prime}$ ' N, 5'16’9.39” E). The Kherrata Dam was constructed at the confluence of the El Berd and Embarek rivers. The average flow of the two rivers is from 2.53 to 5.39 $\mathrm{m}^{3} \mathrm{~s}^{-1}$. The annual average water temperature in Kherrata Reservoir is $15.7^{\circ} \mathrm{C}$, with the lowest temperatures recorded from December to February at a mean of $7^{\circ} \mathrm{C}$ and the warmest noted from June to August at a mean of $24.8^{\circ} \mathrm{C}$.

One hundred and thirty fish (70 females and 60 males) were collected from April 2010 to September 2011 from Kherrata Reservoir. The fish samples were caught with purse seines at 15 day intervals by commercial fishers. Fish of both sexes $(n=130)$ were sacrificed every month for 17 months (although the fish sampled in April were not included in the macroscopic study). The mean length range was $59.5 \mathrm{~cm} \pm$ 4.60 for females and $59.1 \mathrm{~cm} \pm 3.47$ for males. Eviscerated fish weight ranged from 840 to $3035 \mathrm{~g}$ in males and from 930 to $3105 \mathrm{~g}$ in females (Table 1). The age ranged from 4 to 5 years for both sexes. Immediately after collection, live fish were transported to the laboratory. The information recorded for each specimen included measurements of total length (TL) to the nearest mm using a fish measuring board. The fish were then dissected and gonad morphology, size, and color were noted, and the sexes and maturity stages were recorded. The gonads were then weighed to the nearest $0.0001 \mathrm{~g}$ using an electronic balance (Ohaus Adventurer AR2140). Eviscerated fish weight was measured to the nearest $10 \mathrm{~g}$ with a balance hook (Baxtran KRN 10), and the liver weight was recorded later. Monitoring covered two successive spawning seasons. The gonadosomatic index (GSI) and hepatosomatic index (HSI) values were calculated for each individual fish as follows:

$\mathrm{GSI}=$ gonad weight $(\mathrm{g}) \times$ eviscerated weight $(\mathrm{g})^{-1} \times 100$.

$\mathrm{HSI}=$ liver weight $(\mathrm{g}) \times$ eviscerated weight $(\mathrm{g})^{-1} \times 100$.

The ovaries and testes were analyzed at the microscopic level with standard histological techniques. Tissues for histological observation was obtained from the middle of the gonads. The tissues were prepared for histological examination by fixing them in a $10 \%$ neutralized formalin solution. The samples were then dehydrated in increasing ethanol concentrations (70 to $95 \%$ ), cleared in xylene, and embedded in paraffin wax. Histological sections $3 \mathrm{~mm}$ thick were cut with a rotary microtome. The sections were mounted on glass microscope slides, stained with hematoxylin-eosin, and then examined and photographed with an Optika DM binocular digital microscope $(2.0 \mathrm{Mpx})$. The frequencies of the different stages of the ovaries and testes were calculated using the following formula: number of ovaries or testis in a particular stage $\times 100$ per total number of ovaries or testes counted. Oocyte diameters were measured with Echoview software, ant the average oocyte diameters for each month were calculated based on 30-40 oocytes from all of the stained slides in the same month; these values are presented as mean \pm SD. 


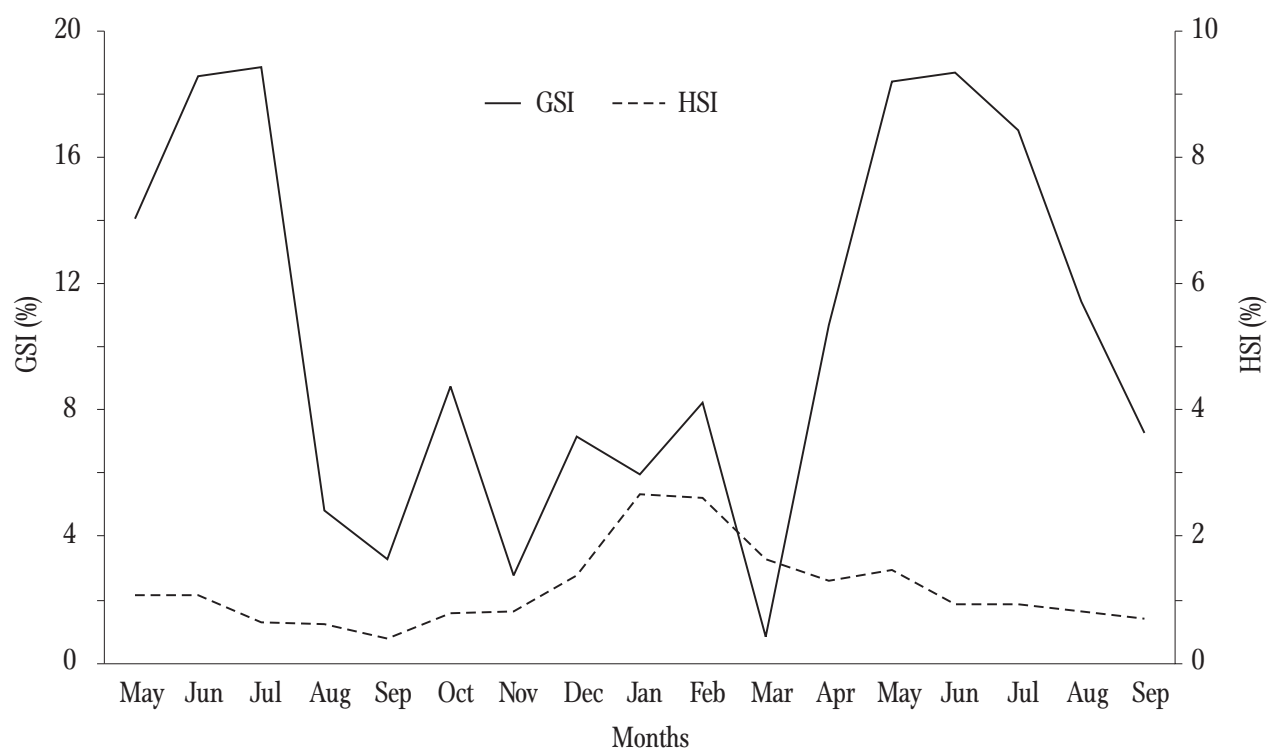

Figure 1. Monthly variation of gonadosomatic index (GSI) and hepatosomatic index (HSI) of H. molitrix female during two successive reproductive seasons in Kherrata Reservoir.

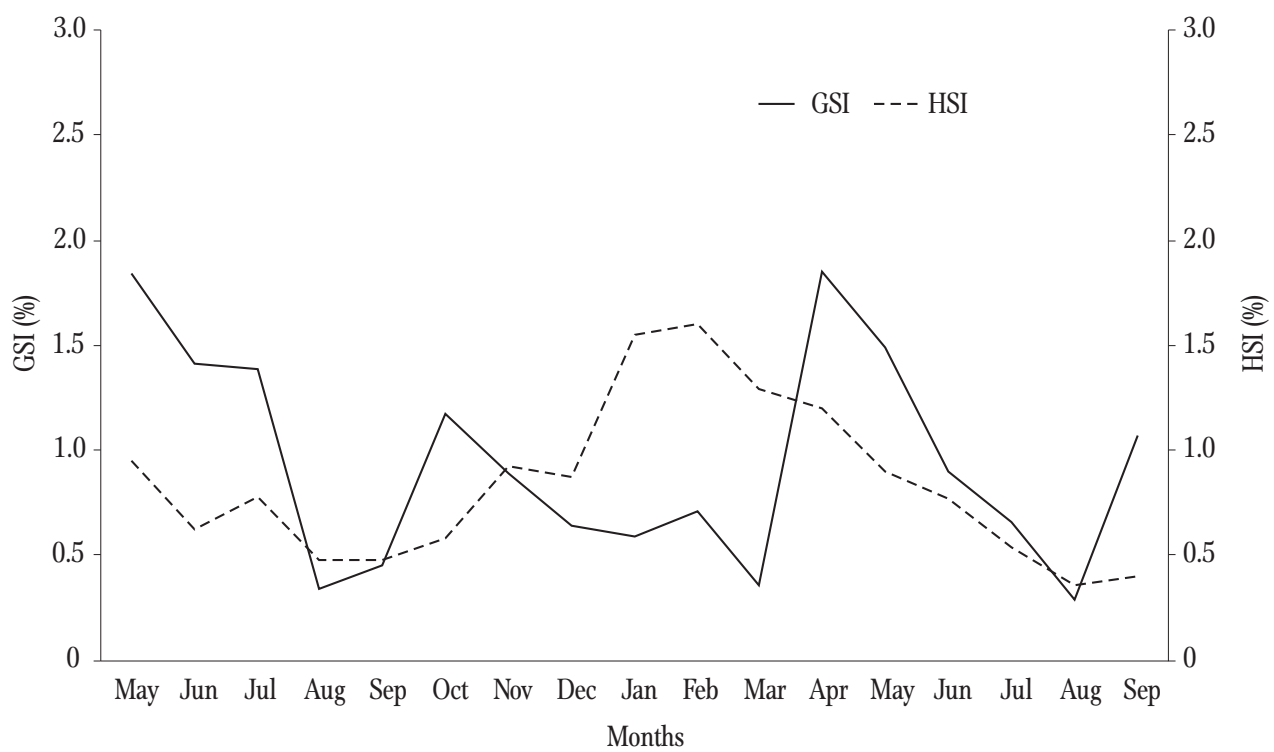

Figure 2. Monthly variation of gonadosomatic index (GSI) and hepatosomatic index (HSI) of H. molitrix male during two successive reproductive seasons in Kherrata Reservoir.

\section{Results}

\section{Macroscopic Study}

\section{Monthly evolution of GSI and HSI}

Female and male GSI variation during the study period is presented in Figs. 1 and 2, respectively. During the 2010 spawning season, female GSI (Fig.1) increased significantly and peaked in July at a value of $18.74 \%$. This was followed by a decrease that reached minimum values in September. The 2011 spawning season was characterized by rapid gonadal development between March and May and a slowed development between May and June. Male GSI values (Fig. 2) peaked in the two spawning seasons in April and May, and they reached the lowest values in August (Fig. 2). The HSI index evolved similarly in 
Table 1

Number of fish analyzed each month, range of total length and eviscerated weight, gonadosomatic index (GSI) and hepatosomatic index (HSI) (mean \pm SD) in male and female H. molitrix

\begin{tabular}{llllllllll}
\hline \hline & & \multirow{2}{*}{$\begin{array}{l}\text { No. of } \\
\text { Months }\end{array}$} & $\mathrm{N}$ & \multirow{2}{*}{$\begin{array}{l}\text { No. of } \\
\text { females }\end{array}$} & & $\begin{array}{l}\text { Gutted } \\
\text { males }\end{array}$ & weight $(\mathrm{g})$ & \multirow{2}{*}{$\begin{array}{l}\text { Total lenght } \\
(\mathrm{cm})\end{array}$} & \multicolumn{2}{l}{ Females } & GSI & HSI & GSI & HSI \\
\hline \hline Apr 10 & 9 & 7 & 2 & - & $56-60$ & - & - & - & - \\
May 10 & 9 & 5 & 4 & $930-2070$ & $46-56.5$ & $14.1 \pm 4.6$ & $1.06 \pm 0.27$ & $1.84 \pm 0.10$ & $0.95 \pm 0.53$ \\
Jun 10 & 7 & 4 & 3 & $840-1900$ & $45-62.2$ & $18.6 \pm 0.1$ & $1.07 \pm 0.08$ & $1.41 \pm 0.35$ & $0.62 \pm 0.13$ \\
July 10 & 6 & 1 & 5 & $1850-2526$ & $60-65$ & $18.88 \pm 0$ & $0.63 \pm 0$ & $1.36 \pm 0.09$ & $0.78 \pm 0.07$ \\
Aug 10 & 4 & 1 & 3 & $1531-2200$ & $57-65$ & $4.84 \pm 0$ & $0.62 \pm 0$ & $0.34 \pm 0.40$ & $0.48 \pm 0.14$ \\
Sep 10 & 5 & 3 & 2 & $1093-1865$ & $52-62.6$ & $3.26 \pm 0.24$ & $0.38 \pm 0.13$ & $0.45 \pm 0.13$ & $0.48 \pm 0.04$ \\
Oct 10 & 7 & 4 & 3 & $1700-2300$ & $59.2-66$ & $8.77 \pm 1.37$ & $0.78 \pm 0.23$ & $1.17 \pm 0.08$ & $0.58 \pm 0.05$ \\
Nov 10 & 6 & 4 & 2 & $1300-1900$ & $53.5-61$ & $2.76 \pm 1.72$ & $0.82 \pm 0.16$ & $0.88 \pm 0.014$ & $0.92 \pm 0.01$ \\
Dec 10 & 4 & 3 & 1 & $1900-2700$ & $58.5-66$ & $7.1 \pm 1.35$ & $1.39 \pm 0.6$ & $0.65 \pm 0$ & $0.87 \pm 0$ \\
Jan 11 & 8 & 5 & 3 & $1500-2050$ & $57.3-64$ & $5.94 \pm 1.32$ & $2.66 \pm 0$ & $0.59 \pm 0.35$ & $1.55 \pm 0.68$ \\
Feb 11 & 4 & 2 & 2 & $1600-2700$ & $57-66.5$ & $8.23 \pm 2.09$ & $2.61 \pm 0.28$ & $0.74 \pm 0.077$ & $1.6 \pm 0.17$ \\
Mar 11 & 6 & 1 & 5 & $1100-2060$ & $49-61.5$ & $0.85 \pm 0$ & $1.63 \pm 0$ & $0.36 \pm 0.61$ & $1.29 \pm 0.48$ \\
Apr 11 & 6 & 2 & 4 & $1560-2400$ & $53-61$ & $10.7 \pm 5.33$ & $1.3 \pm 0.10$ & $1.85 \pm 0.33$ & $1.2 \pm 0.10$ \\
May 11 & 10 & 3 & 7 & 12502200 & $50-65$ & $18.42 \pm 7.6$ & $1.47 \pm 0.27$ & $1.49 \pm 0.90$ & $0.9 \pm 0.36$ \\
Jun 11 & 10 & 6 & 4 & $1630-2139$ & $54.5-62.5$ & $18.72 \pm 0$ & $0.93 \pm 0.23$ & $0.89 \pm 0.67$ & $0.77 \pm 0.22$ \\
July 11 & 9 & 5 & 4 & $1544-3035$ & $59-69$ & $16.85 \pm 6.92$ & $0.93 \pm 0.12$ & $0.66 \pm 0.33$ & $0.54 \pm 0.17$ \\
Aug 11 & 9 & 6 & 3 & $1825-3100$ & $60-71$ & $11.43 \pm 3.16$ & $0.81 \pm 0.10$ & $0.29 \pm 0.17$ & $0.36 \pm 0.23$ \\
Sep 11 & 11 & 8 & 3 & $1482-3030$ & $54-71$ & $7.29 \pm 4.98$ & $0.7 \pm 0.34$ & $1.07 \pm 1.27$ & $0.4 \pm 0.05$ \\
\hline \hline
\end{tabular}

both sexes (Fig. 1 and Fig. 2), and it indicated the development stage during the slowed GSI period of $\mathrm{Au}$ gust 2010 to March 2011 only to decrease in tandem with gonad development.

\section{Gonad macroscopic development stages}

Six macroscopic developmental stages were observed in the females and four in the males. Stage I. The ovaries were underdeveloped, dark colored, and the eggs were not visible. The testicles were thin, pinkish, and vascularized, and they occupied $30-40 \%$ of the body cavity. Stage II. The ovaries were larger and thicker; gray, scattered, and transparent eggs appeared inside the ovaries with the presence of a few blood vessels across the gonads. The testicles were larger, whitish, with occasional blood capillaries, and they occupied one-half of the abdominal cavity; milt ran under moderate pressure. Stage III. The ovaries were light gray, and they occupied almost one-third of the abdominal cavity; the oocytes were more condensed with a whitish color. Fine blood vessels passed through the ovaries. The oocytes could be stripped with moderate pressure. The testes were larger, occupied the entire abdominal cavity, and milt ran under slight pressure. Stage IV. The ovaries were more developed and occupied two-thirds of the abdominal cavity. The oocytes were larger and whitish, and more blood vessels passed over the surface of the ovaries. Testes were significantly decreased in size, and there was no milt production. Stage V. The ovaries were pale yellow and occupied only one third of the abdominal cavity, and there were only a few blood vessels. Yellowish oocytes were observed inside the ovaries. Stage VI. The ovaries were significantly reduced in volume with white scattered oocytes.

\section{Microscopic Study}

\section{Microscopic analysis of silver carp ovaries}

In the current study, six histological stages were observed at the microscopic level (Fig. 3). Stage I (Perinuclear oocytes). This stage can be divided into two phases: chromatin nucleolus follicles 

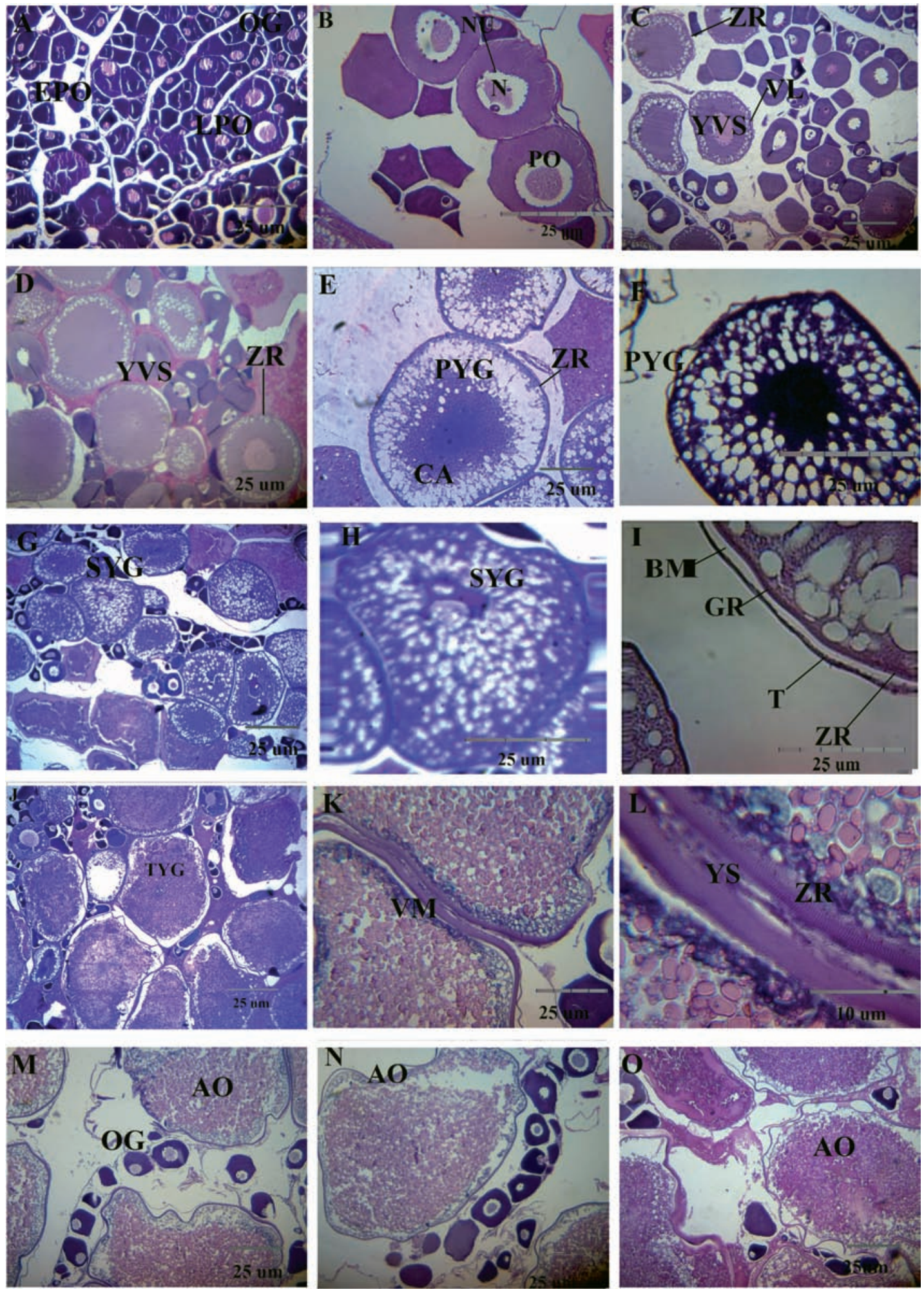

Figure 3. Different stages of oocyte maturation in H. molitrix. A and B) perinuclear oocyte stage: OG: oogonium; EPO - early perinuclear oocytes; LPO: late perinuclear oocytes; Po: perinuclear oocyte; N: nucleus; Nu: nucleolus. C and D) yolk vesicle stage: YVS: yolk vesicle stage; ZR: zona radiata; VL: vittelus. E and F) primary yolk globule stage: PYG: primary yolk globe; CA: cortical alveoli; ZR: zona radiata G and H) Secondary yolk globule stage; SYG: secondary yolk globule. I) BM: basal membrane; T: theca; ZR: zona radiata; GR: granulosa. J) tertiary yolk globule stage: TYG: tertiary yolk globule. K) VM: vitelline membrane. L) YS: yolk space. M, N and O) AO: atretic oocytes; OG: oogonium. 
(oogonium) and perinucleolar oocytes. The oogonium occupied the greatest part of the oocytes, and the cytoplasm was dense and homogeneous (Fig. 3A). Perinucleolar oocytes (Fig. 3B) were irregular spheres with several nucleoli. Nucleoli were variable in size and number (from 3 to 23). The nucleus was eosinophilic. As the oocytes developed, the nucleoli migrated to the periphery of the nucleus. The diameter of oocytes was 75-600 $\mu \mathrm{m}$ with a large nucleus (75-300 $\mu \mathrm{m})$. The chromatin nucleolus follicles and perinuclear oocytes signaled the pre-vitellogenic stage. Stage II (Yolk vesicle stage). The cytoplasm became heterogeneous by the presence of small vesicles organized in a ring at the periphery of the oocytes (Fig. 3C and 3D). This stage was marked by the increased size of the primary oocytes (525-1025 mm). The nuclei (125-450 $\mathrm{mm})$ became increasingly eosinophilic. The nucleoli and nuclear membranes became less regular, and the zona radiata was present between the oocytes and their follicular layers (Fig. 3D). Stage III (Primary yolk stage). Yolk globules occupied one-third of the cytoplasm, and the cortical alveoli appeared in the ooplasm (Fig. 3E and $3 F)$. The nucleus $(300 ? 750 \mathrm{~mm})$ was irregular and the diameter of oocytes were from 550 to $1050 \mathrm{~mm}$. Oil droplets began to appear in the ooplasm around the nucleus with the presence of thin follicular layers enclosing the zona radiata (Fig. 3I). This was the stage of endogen vitellogenesis. Stage IV (Secondary yolk stage). Oocytes (925-1870 mm) and nuclei (450-750 $\mathrm{mm}$ ) increased in size and small protein yolk globules fused into larger ones (Figs. 3G and $3 \mathrm{H})$. Yolk globules increased in number and size and filled two-thirds of the ooplasma. Delicate striations appeared on the zona radiata (Figs. 3K and 3L). Stage $\mathrm{V}$ (Tertiary yolk stage). Protein yolk globules increased and filled the cytoplasm totally (Fig. 3J). Oocytes (1025-2270 mm) and nuclei $(207 \mathrm{~mm})$ reached maximum size. The nucleoli gradually moved to the center. Oil droplets were present only in the periphery of the germinal vesicles. Some oocytes showed early germinal vesicle movement (GVM). Secondary and tertiary yolk stages were the hexogen vittelogenic stages.
Atretic oocytes were very prominent, and the ovaries contained irregular atretic oocytes (Figs. 3M, 3N, 3O). The degeneration pattern was observed in all phases of oocyte development, but it was more common after stage $\mathrm{V}$.

\section{Microscopic analysis of silver carp testes}

Three microscopic developmental stages were observed in the male gonads (Fig.4). Immature testes were characterized by the presence of small seminiferous lobules surrounded by connective tissue. The primary spermatogonia were aligned in the seminiferous tubules (Fig.4A). Cysts with spermatocytes and spermatids surrounded each lobule. Some lobules appeared to be empty.

In maturing testes the lobules were large and separated by interstitial tissue. They contained sparse peripheral, spermatogonia, spermatocyts, and spermatids (Fig. 4B). The number of spermatogonia was reduced, and the number of primary and secondary spermatocytes was the highest. The maturation stage was characterized by reduced numbers of primary and secondary spermatocytes. The volume of the seminiferous tubules was the highest (Figs. 4C, $4 \mathrm{D})$ with the presence of mature spermatozoa.

\section{Monthly distribution of maturity stage}

The distribution of the gonadal development stages during the study period in female and male fish is presented in Figs. 5a and 5b, respectively. The frequency distribution of maturity stages for females (Fig. 5a) varied monthly and no clear distribution pattern was detected throughout the study period. Obviously, stage (I) was noted from March to October with the highest abundance during the month of March (100\%). Stage II oocytes were observed in winter, while stage III were noted between October and April and reached maximum percentages in April (51\%). Stage IV was present from November to August with a peak in February (51\%). Stage V extended from May to July with a peak in May (32\%). Many atretic oocytes were observed in all the development stages with peaks of 50 and $69 \%$ in June and 

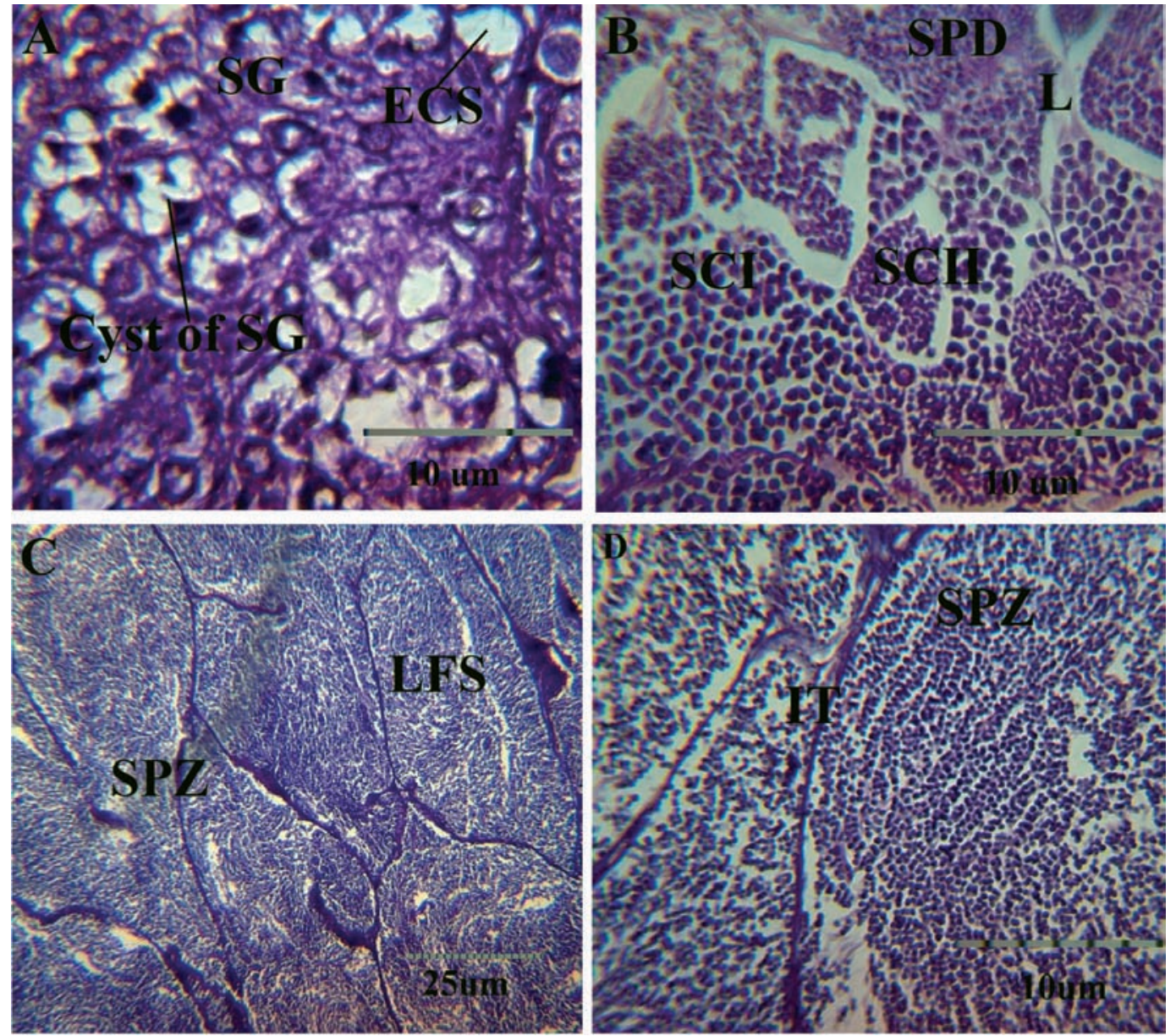

Figure 4. Different stages of testis maturation in H. molitrix. A) immature stage: SG: spermatogonia; ECS: empty cyst of spermatozoa; spermatozoa. B) Testis Maturing stage: SPD: spermatids; SC I and SC II: spermatocyts I and II; L: lumen; ST. C) Mature stage: LFS: Lobule filled with sperm; SPZ: spermatozoa. D) IT: interstitial tissue.

July, respectively. The study of ovarian dynamics showed that $26.08 \%$ of the ovaries were in reproductive stage I, $17.39 \%$ were in stages II and III, 13.04\% were in stage IV, $4.34 \%$ were in stage $\mathrm{V}$, and $21.73 \%$ were atretic oocytes. Spermatogonia (stage I) were noted from September to March with peak abundance from October to March. Spermatids (stage II) were observed from April to May with the maximum in May. Spermatozoids (stage III) were noted from April to September with the highest frequency in June, July, and August (Fig. 5b). The mean follicle diameter (Fig. 6) increased significantly from stage Ia $(0.12 \mathrm{~mm} \pm 0.03)$ to stage $\mathrm{V}(1.41 \mathrm{~mm} \pm 0.50)$. The largest diameters were observed during May and June.

\section{Discussion}

The aim of the present study was to investigate silver carp reproduction in the wild in Algeria. The results showed that females presented significant GSI values from May to July with peaks in June and July, while the male GSI peaked in May and April, two months earlier than the female GSI. It is known that GSI increases concomitantly with gonad maturation, and it reaches maximum values at the onset of the breeding period and decreases abruptly as soon as the breeding period is over (Roy and Mandal 2015). The GSI of the mature females before ovulation ranged from 9.1 to $37.2 \%$ in Uzbekistan (Kamilov and Komrakova 1999), 4.14 to $17.7 \%$ in the Balkhash-Ili basin in Kazakhstan (Karpov et al. 1989), and from 5 to 


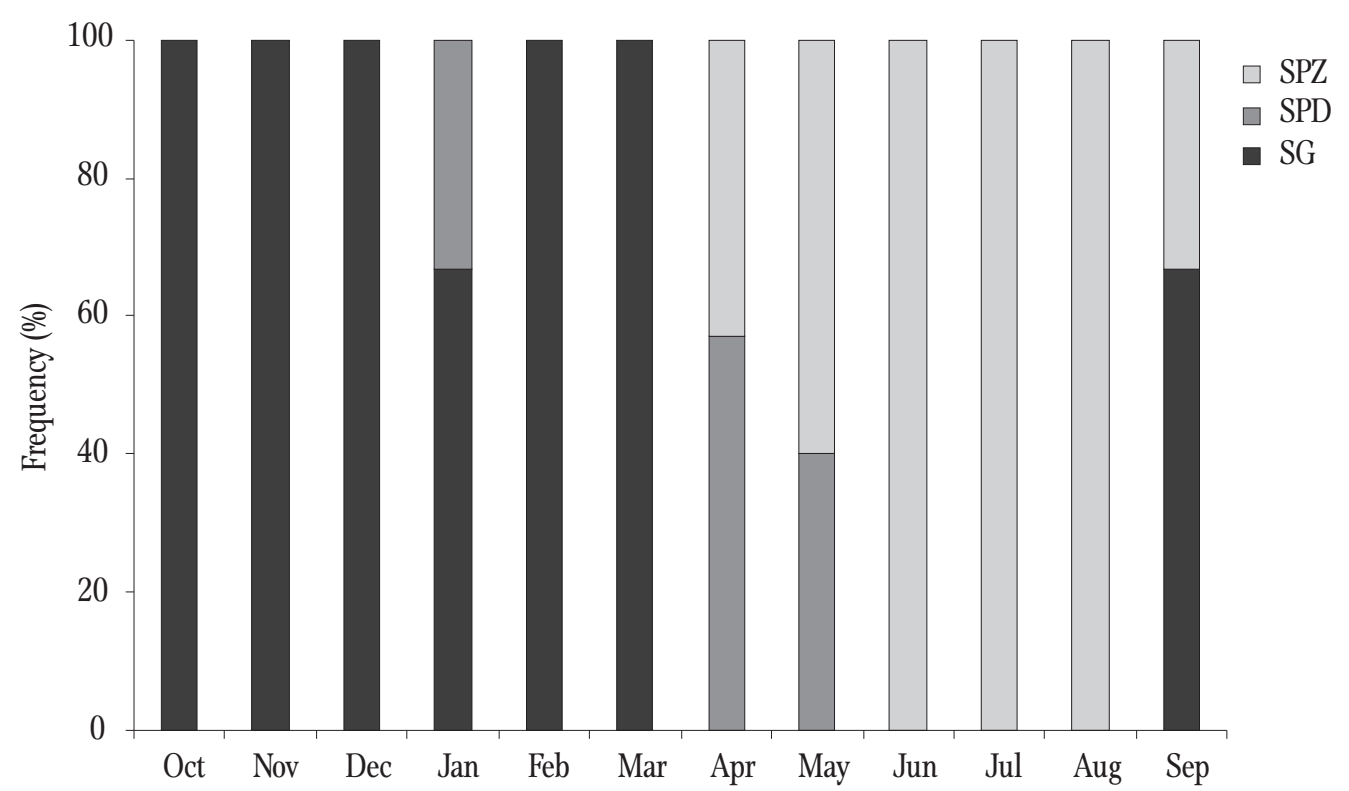

Figure 5. Temporal changes in gonadal maturation stages in females (a) and males (b) of H. molitrix from Kherrata Reservoir. Monthly frequencies (\%) of female and male developmental stages are indicated in color and were compiled from monthly samples for the period from October, 2010 to September, 2011. Stages of sperm maturation: SG - spermatogonium, SPD - spermatids, SPZ - spermatozoa.

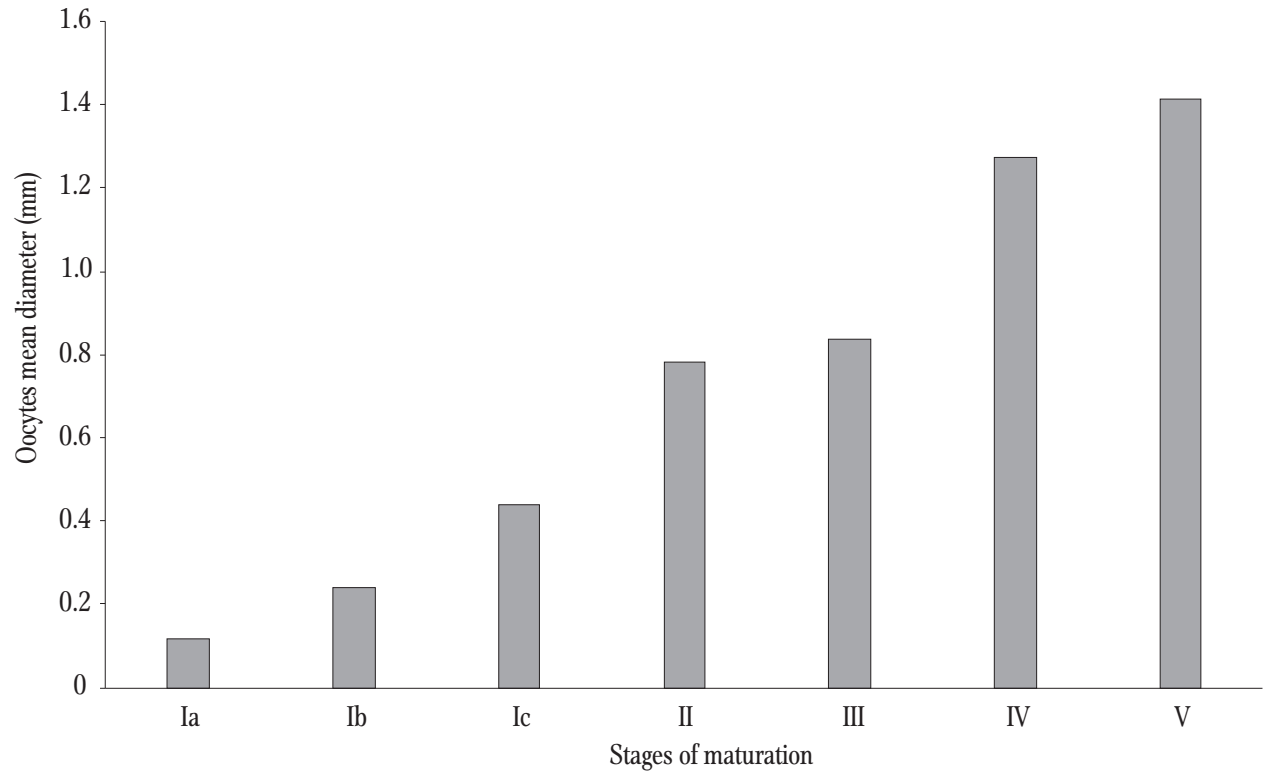

Figure 6. H. molitrix oocyte diameters in different developmental stages.

29.7\% in Syr Darya River in Kyrgyzstan (Kamilov and Salikhov 1996). Temperature is regarded as the main determinant factor in reproduction in the cyprinid family (Billard et al. 1978, Billard 1995).

In fact, oogenesis in silver carp is highly temperature dependent, and, according to Brzuska and Adamek (1987), 1,300-1,400 ${ }^{\circ} \mathrm{D}$ are necessary for spawners to achieve sufficient gonad maturity in
Poland. Normal maturation of silver carp in the Amur River requires an average of $2,865{ }^{\circ} \mathrm{D}$ (Gorbach and Krykhtin 1980). In the current work, maximum ovarian development was noted in June and July when both water temperature and photoperiod reached maximum values $\left(21^{\circ} \mathrm{C}\right.$ and 16L:8D). In the Terek Region of the Caspian Basin, Abdusamadov (1986) reports that introduced silver 
carp spawned from April to July. Silver carp spawning is also reported as follows: mid-May to mid-June in Arkansas; May to July in the Terek River; late May or early June in Uzbekistan; April to July in China; June and July in Japan (Kolar et al. 2005).

The decrease in HSI values during the spawning season could have been attributed to the important role of liver reserves in reproductive activity, which is linked significantly to higher food abundance (Santos et al. 2007) and metabolic rates (Wootton 1998). The relationship between HSI and GSI in H. molitrix indicated an inverse relationship and suggested that hepatic reserves were mobilized during gonad development (Encina and Granado-lorencio 1997, Sudarshan and Kulkarni 2013, Hismayasari et al. 2015).

The study of ova diameter has been demonstrated to be a valuable tool in the evaluation of spawning activity in fish (Sundarabarathy et al. 2004). In fact, in the current results, oocyte diameter was the highest during the spawning months (Roy and Mandal 2015). Growth in oocyte diameter in $H$. molitrix from Kherrata Reservoir was particularly important from stage II. The minimum diameter of oocytes was observed in the chromatin nucleolus stage and the maximum diameter was noted in the tertiary yolk stage. It has been shown previously that the highest oocytes diameters were found from May to June (GSI ? 14), which corresponded to maximum vitellogenin and estrogen synthesis and the onset of the spawning season (Lenhardt and Cakić 2002). In the natural environment of this species, the diameter of the ripe eggs before spawning was 0.6-1.01 $\mathrm{mm}$ in Uzbekistan (Kamilov and Komrakova 1999) and 0.5-1.7 mm in Syr Darya in Kyrgyzstan (Abdullayev and Khakberdiyev 1989), while in the present study the maximum value was $1.4 \mathrm{~mm}$ noted in stage $\mathrm{V}$.

Histological examinations revealed the presence of different oocyte development stages in the same ovaries that indicated asynchronous activity. Histological analysis indicated there were five stages of oocyte development, namely the perinucleolar, yolk vesicle, primary yolk, secondary yolk, and tertiary yolk (early migratory nucleus) stages. Migratory nuclei and hydrated oocytes were not observed. The inhibition of oocyte development was observed in summer when GSI values were the highest and oocytes reached their maximum diameter. This failure is also observed in captive carps, particularly in Labeo rohita (Hamilton) (Lone and Hussain 2009) and Catla catla (Hamilton) (Khalid et al. 2012). Because the environmental conditions in habitats into which these cyprinids have been introduced differ diametrically from those of their natural habitats, these species exhibit reproductive endocrine dysfunction (Podhorec and Kouril 2009) mostly during final oocyte maturation (Yaron 1995). This is caused by the insufficient LH secretion necessary for the activation of final oocyte maturation (Mańanós et al. 2009).

In this study, the H. molitrix testes developed earlier than did the ovaries. Silver carp testes exhibited three stages of development with the presence of mature spermatozoa at the final stage from June to September. The current study provides more information regarding silver carp reproductive failure in Kherrata Reservoir, and females were identified as the limiting factor since no final oocyte maturation was observed.

Acknowledgments. The authors are thankful to the Kherrata Reservoir fishers for providing fish samples. We are also thankful to CNRDPA for financial support.

Author contribution. S.S. designed and performed the research, analyzed the data, and wrote the paper; M.I.O. reviewed the manuscript.

\section{References}

Abdullayev M.A., Khakberdiyev B. 1989 - Problems of biology and ecology of Grass Carp and Silver Carp from collecting-drainage waters of middle and lower reaches of Syr Darya - In: Annotated bibliography of bighead (Hypophthalmichthys nobilis) and silver (Hypophthalmichthys molitrix) carps from Russian-language literature (Eds) N.G. Bogutskaya, L.A. Jones, N.E. Mandrak, B. Cudmore. Can. Manuscr. Rep. Fish. Aquat. Sci.

Abdusamadov A.S. 1986 - Biology of white amur, Ctenopharyngodon idella, Silver carp, Hypophthalmichthys molitrix, and bighead, Aristichthys nobilis, acclimatized in the Terek region of the Caspian basin - J. Ichthyol. 3: 425-433.

Billard R., Breton B., Fostier A., Jalabert B., Weil C. 1978 Endocrine control of the teleost reproductive cycle and its relation to external factors: salmonid and cyprinid 
models - In: Comparative Endocrinology (Eds) P.T. Gaillard, H.H. Boer, Elsevier North Holland Biomedical Press, Amsterdam: 37-48.

Billard R. 1995 - Carp: Biology and culture - Billard, Paris, France, $342 \mathrm{p}$.

Brzuska E., Adamek J. 1987 - Investigation on the reproduction of the herbivorous fish Ctenopharyngodon idella, Hypophthalmichtys molitrix and Aristichthys nobilis under controlled conditions - Acta Hydrobiol. 29: 497-508.

Encina L., Granado-Lorencio C. 1997 - Seasonal changes in condition nutrition, gonad maturation and energy content in barbel, Barbus scaleteri, inhabiting a fluctuating river - Environ. Biol. Fish. 50: 75-84.

Gorbach E.I., Krykhtin M.L. 1980 - optimal parameters of the main factors determining maturation and reproduction of Grass Carp and Silver Carp in the Amur - In: Phytophagous fishes in industrial fish culture - Book of Abstracts of the 9th All-Union Conference: 152-154.

Herborg L.M., Mandrak N.E., Cudmore B.C., Macisaac H.J. 2007 - Comparative distribution and invasion risk of snakehead (Channidae) and Asian carp (Cyprinidae) species in North America - Can. J. Fish. Aquat. Sci. 29: 1723-1735.

Hismayasari I.B., Marhendra A.P.W., Rahayu S., Saidin S.D.S. 2015 - Gonadosomatic index (GSI), hepatosomatic index (HSI) and proportion of oocytes stadia as an indicator of rainbowfish Melanotaenia boesemani spawning season Int. J. Fish. Aquat. Stud. 2: 359-362.

Jankovic D. 1998 - Natural reproduction by Asiatic herbivorous fishes in the Yugoslav section of the River Danube Ital. J. Zool. 65: 227-228.

Kamilov B.G., Komrakova M.Y. 1999 - Maturation and fecundity of the silver carp, Hypophthalmichthys molitrix, in Uzbekistan - Isr. J. Aquac. (Bamidgeh) 51: 40-43.

Kamilov B.G., Salikhov T.V. 1996 - Spawning and reproductive capability of Silver Carp Hypophthalmichthys molitrix in Syr Darya River - Vopr. Ikhtiologii 36: 631-637.

Karpov V.E., Bayekeshev A.Sh., Glukhovtsev I.V., Shapovalov M.V. 1989 - Characteristics of self-sustained stocks of Grass Carp and Silver Carp in the Silver Carp populations in the Ili River including Balkash Lake and the Balkhash-Ili basin Darya - In: Annotated bibliography of bighead (Hypophthalmichthys nobilis) and silver (Hypophthalmichthys molitrix) carps from Russian-language literature (Eds) N.G. Bogutskaya, L.A. Jones, N.E. Mandrak, B. Cudmore. Can. Manuscr. Rep. Fish. Aquat. Sci.

Khalid P.L., Sumrin S., Shafek F. 2012 - Age-related change in ovarian gross and histological characteristics during pubertal development in captive Catla catla (Hamilton, 1822) of age 18-29 months - Pak. J. Zool. 44: 159-172.

Kolar C.S., Chapman D.C., Walter, R., Courtenay J.R., Housel R.S., Wiliams C.M., Jennigs D.P. 2005 - Asian carps of the genus Hypophthalmichthys (Pisces, Cyprinidae): a biological synopsis and environmental risk assessment,
Report 94400-3-0128 to the U.S. Fish and Wildlife Service, Washington.

Krykhtin M.L., Gorbach E.I. 1981 - Reproductive ecology of grass carp, Ctenopharyngodon idella, and the silver carp, Hypophthalmichthys molitrix, in the Amur basin - J. Ichthyol. 21: 109-123.

Lenhardt M., Cakić P. 2002 - Seasonal reproductive cycle of pike, Esox lucius L., from the river Danube - J. Appl. Ichthyol. 18: 7-13.

Lone K.P., Hussain A. 2009 - Seasonal and age related variations in the ovaries of Labeo rohita and histological study of gametogenesis, maturation and fecundity - Pak. J. Zool. 41: 217-234.

Mańanós E., Duncan N., Mylonas C. 2009 - Reproduction and control of ovulation, spermiation and spawning in cultured fish - In: Methods in reproductive aquaculture marine and freshwater species (Eds) E. Cabrita, V Robles, M.P. Herráez, CRC Press, Taylor and Francis Group, Boca Raton: 3-80.

Podhorec P., Kouril J. 2009 - Induction of final oocyte maturation in Cyprinidae fish by hypothalamic factors: a review - Vet. Med.-Czech 54: 97-110.

Roy K., Mandal D.K. 2015 - Maturity stages of ovary of a minor carp, Labeo bata (Hamilton-Buchanon, 1822) Int. J. Fish. Aquat. Stud. 2: 19-24.

Santos A.M.P., Ch'1charo A., Dos Santos T., Moita P. B., Oliveira A. Peliz P. R. 2007 - Physical-biological interactions in the life history of small pelagic fish in the Western Iberia Upwelling Ecosystem - Progr. Oceanogr. 74: 192-209.

Schrank S.J., Guy C.S. 2002 - Age, growth, and gonadal characteristics of adult bighead carp, Hypophthalmichthys nobilis, in the lower Missouri River - Environ. Biol. Fish. 64: 443-450.

Stott B., Cross D.G. 1973 - A note on the effect of lowered temperature on the survival of eggs and fry of the grass carp (Ctenopharyngodon idella Val.) - J. Fish Biol. 5: 649-658.

Sudarshan S., Kulkarni R.S. 2013 - Determination of Condition Factor (K) Somatic Condition Factor (Ks) Hepatic and Gonado Somatic Indices in The Fresh Water Fish Notopterus Notopterus - Int. J. Sci. Res. 2: 524- 526.

Sundarabarathy T.V., Edirisinghe U., Dematawewa C.M.B. 2004 - Captive breeding and rearing of fry and juveniles of cherry barb (Puntius titteya deraniyagala), a highly threatened endemic fish species in Srilanka - Trop. Agr. Res. 16:137-149.

Wootton R.J. 1998 - Ecology of teleost fishs - Chapman and Hall, London, New York, 404 p.

Xu P., Li J., Li Y., Cui R., Wang J., Zhang J., Zhao Z., Sun X. 2011 - Genomic insight into the common carp (Cyprinus carpio) genome by sequencing analysis of BAC-end sequences - BMC Genomics 12: 1-7.

Yaron Z. 1995 - Endocrine control of gametogenesis and spawning induction in the carp - Aquaculture 129: 49-73. 